\title{
Copper deficiency myeloneuropathy in a patient with previous bariatric surgery
}

\author{
Alexander J. Arnold MD, Aleksander Tkach MD, Daryl J. Wile MD
}

- Cite as: CMAJ 2019 August 6;191:E866. doi: 10.1503/cmaj.190168

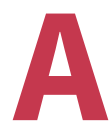

54-year-old woman was referred for neuropathic pain after a suicide attempt. She reported progression of painful paresthesias in her feet spreading to her thighs and hands, and 6 months of leg weakness and imbalance leading to a dependent state. Her medical history was notable for multiple bariatric surgeries beginning at age 15 years with a jejunoileal bypass, which required multiple revisions and a Roux-en-Y gastrojejunostomy at age 47 years. The patient ate a standard diet and received supplemental vitamins $A, D, E, K, B_{12}$ and iron. Examination showed quadriparesis, diffuse hyperreflexia excluding the masseter and Achilles reflexes, and severe proprioceptive and vibration sense loss. These findings suggested myeloneuropathy, and the patient's surgical history suggested a malabsorption syndrome.

Serum investigations showed normocytic anemia, normal vitamin $B_{12}$ and zinc levels, but a low copper level of 3.9 (normal 10-22) $\mu \mathrm{mol} / \mathrm{L}$. Magnetic resonance imaging (MRI) of the cervical spine showed longitudinally extensive inverted "V" $T_{2}$ hyperintensity of the posterior column suggestive of $B_{12}$ or copper deficiency (Figure 1).

Copper deficiency is an uncommon but treatable cause of neurologic morbidity that is usually due to gastrointestinal surgery or excess zinc intake. Its presentation resembles the subacute combined degeneration of spinal cord caused by $B_{12}$ deficiency. ${ }^{2}$ The typical findings on MRI of the spine, as seen in our patient (Figure 1), can also be seen in posterior spinal artery infarct, inflammatory demyelination, tabes dorsalis, HIV, human T-lymphotropic virus, nitrous oxide inhalation (causing $B_{12}$ deficiency), cyanide toxicity (e.g., konzo), radiation myelopathy and methotrexate toxicity. ${ }^{1}$

Copper deficiency develops in 10\%-20\% of patients who have undergone Roux-en-Y gastrojejunostomy, and postoperative copper supplementation is recommended. ${ }^{3}$ In copper deficiency, treatment with intravenous or oral copper is adjusted to serum copper response, and is expected to stabilize symptoms. ${ }^{2}$ Improvement of neurologic symptoms is variable. ${ }^{2}$ Our patient received oral and intravenous copper supplementation and, in the initial months of intensive rehabilitation, showed some functional improvement, allowing her to transfer with assistance and operate a wheelchair.

\section{References}

1. Cho TA, Bhattacharyya S. Approach to myelopathy. Continuum (Minneapolis, Minn) 2018;24(2, Spinal cord disorders):386-406.

2. Chhetri SK, Mills RJ, Shaunak S, et al. Copper deficiency. BMJ 2014;348:g3691.

3. Parrott J, Frank L, Rabena R, et al. American Society for Metabolic and Bariatric Surgery integrated health nutritional guidelines for the surgical weight loss patient 2016 update: micronutrients. Surg Obes Relat Dis 2017;13:727-41.

\section{Competing interests: None declared.}

This article has been peer reviewed.

The authors have obtained patient consent.

Affiliations: Department of Clinical Neurosciences and The Hotchkiss Brain Institute (Arnold), University of Calgary, Calgary, Alta.; Southern Medical Program (Tkach, Wile), The University of British Columbia, Okanagan Campus, Kelowna, BC

Correspondence to: Alexander Arnold, arnoldaj@ucalgary.ca 